\title{
Oxazoline-based crosslinking reaction for coatings
}

\author{
Philipp Knospe, Patrick Böhm, Jochen Gutmann, Michael Dornbusch
}

Received: 26 September 2020 / Revised: 24 January 2021 / Accepted: 1 February 2021

(C) The Author(s) 2021

\begin{abstract}
Nowadays, coating materials must meet high demands in terms of mechanical, chemical and optical properties in all areas of application. Amongst others, amines and isocyanates are used as crosslinking components for curing reactions, meeting the highly demanding properties of the coatings industry. In this work, a new crosslinking reaction for coatings based on oxazoline chemistry is investigated with the objective to overcome disadvantages of established systems and fulfill the need for sustainable coating compounds. The oxazoline-group containing resin, synthesized from commercially available substances, undergoes cationic self-crosslinking polymerization to build up a network based on urethane and amide moieties. NMR-, IR- and ES-mass spectroscopy are suitable techniques to characterize the synthesized oxazoline monomers, which are linked to polyisocyanates and polymerized afterwards via self-polymerization. The progress of crosslinking is followed by changes in IR spectra and by rheological measurements to calculate time depen-
\end{abstract}

Supplementary Information The online version contains supplementary material available at https://doi.org/10.1007/s11998021-00479-9.

P. Knospe, P. Böhm, M. Dornbusch ( $\square)$

Department of Chemistry and Institute for Coating and

Surface Technology ILOC, Niederrhein University of

Applied Sciences, Adlerstr. 1, 47798 Krefeld, Germany

e-mail: michael.dornbusch@hs-niederrhein.de

P. Knospe

e-mail: Philipp.Knospe@hs-niederrhein.de

P. Böhm

e-mail: Patrick.Boehm@hs-niederrhein.de

\section{J. Gutmann}

Physical Chemistry \& CENIDE, Department of Chemistry, University of Duisburg-Essen, Universitätsstr. 2, 45141

Essen, Germany

e-mail: jochen.gutmann@uni-due.de dent values for storage and loss modulus. The glass transition temperature of the resulting coating is determined, too. Furthermore, sol-gel-analysis is performed to determine the degree of crosslinking. After application on steel and aluminium panels, application tests are performed. In addition to excellent adhesion to the substrate, the polymer network shows promising mechanical properties and with that it could represent a new technology for the coatings industry.

Keywords Oxazoline, Self-crosslinking, Polyurethane, DMTA, Network

\section{Introduction}

Typically, the coatings industry roughly applies two kind of coatings: On one hand physically drying, nonreactive systems are used, if lower-end applications and ease of handling are in the focus. On the other hand, if high durability and enhanced mechanical properties are requested, reactive systems based on reacting active groups of a crosslinking agent with a resin are used. Advantages of the latter method are the resulting high durability, better corrosion protection as well as better chemical and mechanical resistance of such coatings in comparison to physically dried coatings. In general, reactive systems involve functional groups such as melamine, epoxy, amines or isocyanates, which are used to form crosslinked polymer networks. ${ }^{1}$

In order to create more sustainable systems, the coatings industry aims to develop new crosslinking mechanisms, such as the non-isocyanate polyurethane (NIPU) technologies. ${ }^{2}$ Promising results have already been reported by Wunschik et al. ${ }^{3,4}$ by means of cyclic carbonates as crosslinking-agents producing polyester networks. The crosslinked coatings show pendulum dumping values of 79 and good adhesion on steel substrates without using isocyanates, amines or mela- 
mine as crosslinking agents. In NIPU technologies, cyclic (poly) carbonates are often used in combination with amines to form polyurethane networks, which are sensitive to hydrolysis.

However, drawbacks of the NIPU technologies often outweigh their advantages with regard to the coatings properties. The most used technologies are chemically similar to the isocyanate compounds or the similar polyurethane network will be achieved, and therefore, the origin technology can hardly be replaced because the new technologies just copy the origin one with often drawbacks in the final coating properties or the synthesis of the compounds.

To achieve coatings with new properties based on new network formation with promising chemical and mechanical properties, new crosslinking reactions have to be studied. Oxazolines as reacting active groups show acid catalysed self-polymerization to form poly oxazolines as described by Kobayashi and Uyama. ${ }^{5}$ This cationic polymerization is well-known and finds application in pharmaceutical drug delivery systems. ${ }^{6-8}$ Due to the fact that the synthesis of oxazolines is based on commercially available raw materials and a stable network can be formed, oxazolines represent promising candidates for new crosslinking agents in the coating industry.

In this paper, the crosslinking behavior of oxazolinegroup containing resins and the mechanical properties of the produced coatings are studied.

Here, commercially available raw materials are used as starting materials. 2,4-Dimethyl-4-methylol-2-oxazoline 1, containing a hydroxyl group available for the reaction with polyisocyanates, is synthesized from 2amino-2-methyl-1,3-propandiol and acetic acid as shown in step 1 of Fig. 1. Upon reaction of the hydroxyl group of the oxazoline $\mathbf{1}$ with a hexamethylene diisocyanate trimer (HDI-trimer), a polyisocyanate-oxazoline adduct, IUPAC called $(2,4-$ dimethyl-5H-oxazol-4-yl)-methyl-N-[6-[3,5-bis[6-[(2,4dimethyl-5H-oxazol-4-yl)-methoxycarbonylamino]hexyl]-2,4,6-trioxo-1,3,5-triazinan-1-yl]-hexyl]-carbamate) 2 based on urethane moieties, is formed (see Fig. 1 step 2). The polymeric resin $\mathbf{2}$ is then able to undergo a self-crosslinking reaction upon curing as pictured in step 3 in Fig. 1 to form a network based on urethane and amide moieties 3.

\section{Experimental}

\section{Raw materials}

HDI-trimer was provided by Covestro Deutschland AG. 2-Amino-2-methyl-1,3-propandiol (min. 98\%) was purchased from TCI Europe. All other compounds were purchased from Aldrich Chemicals and have been used without further purification.
4Fig. 1: Synthesis of the new oxazoline compounds and the network formation

All coatings have been applied on steel samples (DX51D+Z), aluminium samples (type A199,5) or glass plates.

\section{Analytical methods}

${ }^{1}$ H-NMR spectra were measured on a Bruker Fourier 300 spectrometer at $300 \mathrm{MHz}$. $\mathrm{CDCl}_{3}$ has been used as solvent and internal standard.

Mass spectra were measured with a 6530 Q-TOF LC/MS system from Agilent (Agilent, Santa Clara, USA) using a Polaris Amid C18 column (Agilent, Santa Clara, USA) and Dual AJS ESI ionization mode.

IR spectra were measured on a Bruker Lumos FTIR-Microscope or with the Bruker Vertex 70 FTIRspectrometer $\left(4000-375 \mathrm{~cm}^{-1}\right)$ with a resolution of $4 \mathrm{~cm}^{-1}$.

The rheological experiments to achieve values for storage and loss modulus and the glass transition temperature have been performed on a Modular Compact Rheometer MCR 102 (Anton-Paar) using Plate-Plate-single use with a diameter of $25 \mathrm{~mm}$ and a slot of $1 \mathrm{~mm}$. Solvent containing samples have been dried overnight at $70^{\circ} \mathrm{C}$ prior to the measurement. The sample still may contain solvent residues, which can affect measurement data during crosslinking reaction and the values for $G^{\prime}$ and $G^{\prime \prime}$ are always lower in comparison to DMA measurements of a free film because the plate-plate single use system influences measuring data by the diameter of the plate. The diameter of $25 \mathrm{~mm}$ is a compromise to gain accurate data in all steps of the curing reaction.

The pendulum damping values have been obtained according to DIN EN ISO 1522 using a Königspendel from Erichsen. Three measurements for each panel were performed.

Adhesion was received by performing the crosshatch test according to DIN EN ISO 2409. Each panel was measured five times and the average values are given.

\section{Synthesis of the compounds}

\section{2,4-Dimethyl-4-methylol-2-oxazoline 1}

First, 0.25 mol 2-amino-2-methylpropan-1,3-diol and 0.25 mol acetic acid are added under nitrogen atmosphere to a $250 \mathrm{~mL}$ two-necked flask equipped with a magnetic stirrer and a water separator. After adding 
Step 1: Synthesis of 2,4-Dimethyl-4-methylol-2-oxazoline 1<smiles>CC(=O)NC(C)(CO)CO</smiles>

Step 2: Reaction of $\mathbf{1}$ with polyisocyanate to produce the resin $\mathbf{2}$

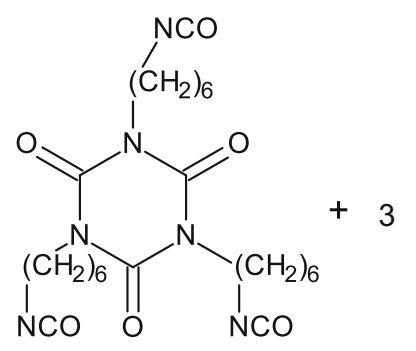<smiles>CC1=NC(C)(CO)CO1</smiles><smiles>Ic1ccccc1</smiles><smiles></smiles><smiles>CNC(=O)OCC1(C)COC(C)=N1</smiles>

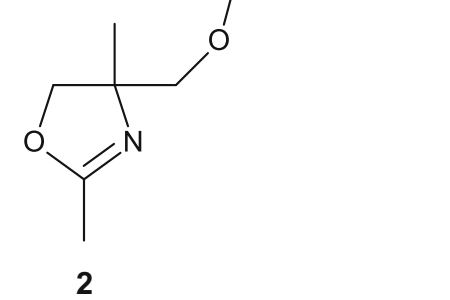

Step 3: Self-Crosslinking reaction of $\mathbf{2}$ to the network $\mathbf{3}\left(\mathrm{R}_{1}\right.$ : HDI-trimer backbone)

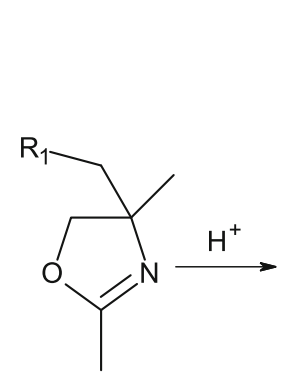

2<smiles>[R]CC1(C)COC(C)=N1</smiles><smiles>[R]CC(C)(C)N(C)C(C)(CN(C)C(C)=O)N(C)C(C)=O</smiles> 
$120 \mathrm{~mL}$ xylene, the mixture is heated to $120^{\circ} \mathrm{C}$ to achieve a clear solution. The temperature is further increased to $160^{\circ} \mathrm{C}$ upon reaction and water separation. After the theoretical amount of water is collected, xylene is removed under reduced pressure, followed by distillation of the product $\mathbf{1}$ at $130^{\circ} \mathrm{C}, 20$ mbar.

Yield: $60 \%$ with a purity of min. $99 \%$.

$M_{w}: 129 \mathrm{~g} / \mathrm{mol}$.

${ }^{1} \mathrm{H}-\mathrm{NMR}\left(300 \mathrm{MHz}, \mathrm{CDCl}_{3}, \delta, \mathrm{ppm}\right): 1.22(3 \mathrm{H}$, $\left.\mathrm{s},-\mathrm{CH}_{3}\right) ; 1.99\left(3 \mathrm{H}, \mathrm{s},-\mathrm{CH}_{3}\right) ; 3.33-3.43(2 \mathrm{H}, \mathrm{s}, J=11.1 \mathrm{~Hz}$, $\left.\mathrm{CH}_{3}-\mathrm{C}-\mathrm{CH}_{2}-\mathrm{O}\right) ; 3.56-3.67\left(2 \mathrm{H}, \mathrm{s}, J=11.0 \mathrm{~Hz}, \mathrm{CH}_{3}-\right.$ $\left.\mathrm{C}-\mathrm{CH}_{2}-\mathrm{O}\right) ; 3.85-3.95\left(2 \mathrm{H}, \mathrm{s}, J=8.0 \mathrm{~Hz}, \mathrm{HO}-\mathrm{CH}_{2}-\mathrm{C}\right)$; $4.28-4.36\left(2 \mathrm{H}, \mathrm{s}, J=8.0 \mathrm{~Hz}, \mathrm{HO}-\mathrm{CH}_{2}-\mathrm{C}\right)$.

(Spectrum in supplementary material, Fig. S1).

IR (resonance in $\left[\mathrm{cm}^{-1}\right]$ and type): $3223(\mathrm{OH}$ valence), $2968\left(\mathrm{CH}_{3}\right.$ stretch $), 2930\left(\mathrm{CH}_{2}\right.$ stretch $)$, $2869\left(\mathrm{CH}_{3}\right.$ stretch), 1668 (CC deformation), 1438 (OH deformation), 1388 ( $\mathrm{CH}_{2}$ wagging), $1238\left(\mathrm{CH}_{2}\right.$ twist), 1057 (C-OH, C-O valence), 1034 (=C-O-C valence), $987\left(\mathrm{CH}_{3}\right.$ rocking $)$, compare Xavier and Prabaharan ${ }^{9}$ and Hesse et al. ${ }^{10}$

(Spectrum in supplementary material, Fig. S2).

MS: $130 \mathrm{~g} / \mathrm{mol}\left(\mathrm{M}^{+}+1\right)$.

(Graph in supplementary material, Fig. S3).

\section{Polyisocyanate-oxazoline adduct 2}

First, 0.04 mol HDI-trimer and $46.7 \mathrm{~mL}$ methyl ethyl ketone (MEK) are added under nitrogen atmosphere to a $500 \mathrm{~mL}$ three-necked flask equipped with a dropping funnel and magnetic stirrer. The solution is heated to $50^{\circ} \mathrm{C}$. Then, $0.12 \mathrm{~mol}$ 2,4-dimethyl-2-methylol-2-oxazoline $\mathbf{1}$ is added dropwise. After complete addition of $\mathbf{1}$, the temperature is increased to $70^{\circ} \mathrm{C}$. The reaction course is controlled using IR spectroscopy. Within $2-4 \mathrm{~h}$ the reaction is completed. The product $\mathbf{2}$ is used without further purification, contained methyl ethyl ketone is used as a solvent and to decrease viscosity of the polyisocyanate-oxazoline adduct.

Yield: $95 \%$ with a purity of $\min .98 \%$.

M: $892 \mathrm{~g} / \mathrm{mol}$.

IR (resonance in $\left[\mathrm{cm}^{-1}\right]$ and type): $3352(\mathrm{NH}-\mathrm{COO}$ and $\mathrm{NH}$ stretch $\left.^{12}\right), 2974\left(\mathrm{CH}_{3}\right.$ stretch $), 2937\left(\mathrm{CH}_{2}\right.$ stretch $\left.^{11}\right), 2904\left(\mathrm{CH}_{x}\right.$ stretch $), 2862\left(\mathrm{CH}_{3}\right.$ stretch $), 1712$ amide $\mathrm{I}^{10}(\mathrm{C}=\mathrm{O}$, urethane $), 1683$ amide $\mathrm{II}^{10}(\mathrm{C}=\mathrm{O}$, urethane, isocyanurate $\left.{ }^{12}\right), 1525(\mathrm{NH}-\mathrm{COO}$ and $\mathrm{NH}$ bending $\left.{ }^{11}\right), 1462$ (NH-COO and $\mathrm{NH}$ bending, isocyanurate $\left.^{2}\right), 1365,1238\left(\mathrm{CH}_{2}\right.$ twist $), 1038$ (=C-O-C valence), $991\left(\mathrm{CH}_{3}\right.$ rocking $), 765(\mathrm{C}-\mathrm{N}$ stretch, isocyanurate $\left.^{12}\right), 729\left(\mathrm{CH}_{2}\right.$ rocking $\left.^{12}\right)$, compare Ming et al. ${ }^{11}$ and Defeyt et al. ${ }^{12}$

(Spectrum in supplementary material, Fig. S4).

MS: $914 \mathrm{~g} / \mathrm{mol}\left(\mathrm{M}^{+}+\mathrm{Na}\right)$ (from the device), 892 $\left(\mathrm{M}^{+}\right), 130$ (oxazoline $\mathbf{1}$ ).

(Spectrum in supplementary material, Fig. S5).
Table 1: Screening of different catalysts using curing temperatures $190^{\circ} \mathrm{C}$ and $160^{\circ} \mathrm{C}$

\begin{tabular}{lll}
$\begin{array}{c}\text { Curing temperature } \\
\text { Added catalyst (0.5\%) }\end{array}$ & $\begin{array}{c}190^{\circ} \mathrm{C} \\
\text { Network } \\
\text { formation }\end{array}$ & $\begin{array}{c}160^{\circ} \mathrm{C} \\
\text { Network } \\
\text { formation }\end{array}$ \\
\hline Without & No & No \\
Sn(IV) chloride & Yes & Yes \\
Cadmium acetate dihydrate & Yes & No \\
Sulphuric acid & Yes & No \\
Succinic acid & Yes & No \\
Phosphoric acid (conc.) & No & No \\
Citric acid & No & No \\
Acetic acid & Yes & No \\
Methyl tosylate & No & No \\
\hline
\end{tabular}

Table 2: Coating properties at different curing temperatures using various catalysts

\begin{tabular}{lccc}
$\begin{array}{l}\text { Baking } \\
\text { temperature }\left({ }^{\circ} \mathrm{C}\right)\end{array}$ & Catalyst & $\begin{array}{c}\text { Pendulum } \\
\text { damping }\end{array}$ & $\begin{array}{c}\text { Impact } \\
\text { test } \\
(1 \mathrm{~m} \\
\text { height })\end{array}$ \\
\hline 140 & $/$ & 62 & $\begin{array}{l}\text { Cracked } \\
\text { Partly } \\
190\end{array}$ \\
& $/$ & 92 & cracked \\
190 & $\mathrm{SnCl}_{4}$ & 158 & Ok \\
190 & PTSA & 101 & Ok \\
190 & $\begin{array}{r}\text { Acetic } \\
\text { acid }\end{array}$ & 112 & Ok \\
& & \\
\hline
\end{tabular}

\section{Application testing}

For application testing, a formulation consisting of $\mathbf{2}$ and $0.5 \%$ catalyst is prepared. The formulation is applied by drawing down a bar on aluminium sheets and curing at 160 and $190^{\circ} \mathrm{C}$ (see Tables 1 and 2) for 30 min to achieve a dry film thickness of $70 \mu \mathrm{m}$.

\section{Results and discussion}

In this work, the self-polymerization of oxazoline derivatives is studied as a new crosslinking mechanism. A novel polyisocyanate-oxazoline adduct $\mathbf{2}$ has been prepared by reacting polyisocyanate and $\mathrm{OH}$-functionalized oxazoline $\mathbf{1}$ upon urethane formation. The crosslinking ability of the obtained adduct $\mathbf{2}$ is based on a cationic polymerization of the oxazoline moiety and occurs according to the mechanism illustrated in Fig. 2, published by Aoi and Okada. ${ }^{13}$ 


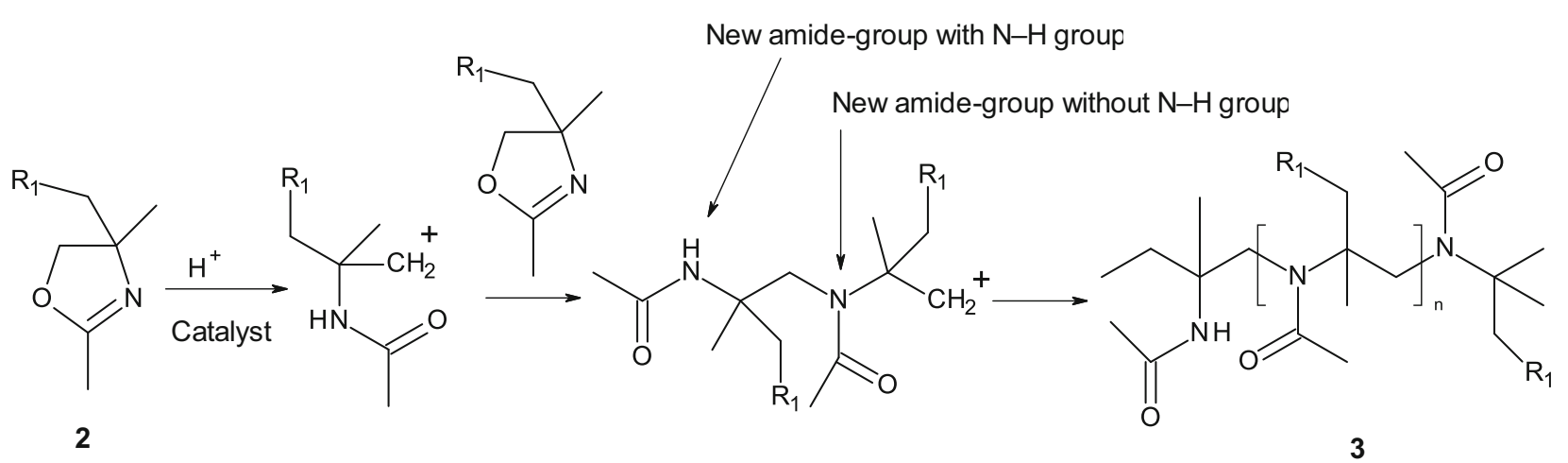

Fig. 2: Mechanism of the cationic polymerization of polyisocyanate-oxazoline adduct 2 ( $R_{1}=\mathrm{HDI}$-trimer backbone) according to Aoi and Okada ${ }^{13}$

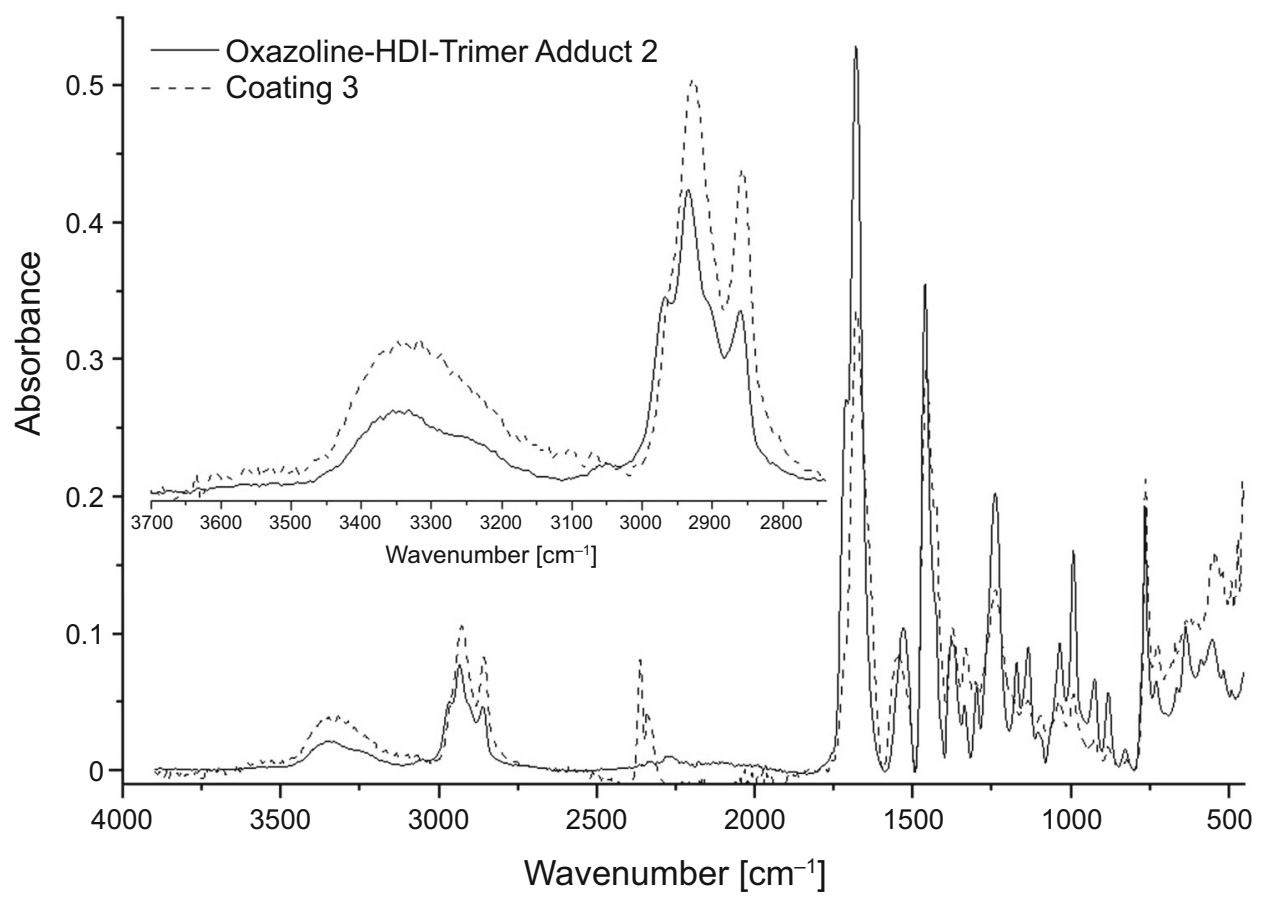

Fig. 3: ATR spectra of $2\left(0.5 \% \mathrm{SnCl}_{4}, 75 \%\right.$ in MEK) and the cured coating 3 after 30 minutes at $190^{\circ} \mathrm{C}$ applied on steel samples (DX51D+Z)

To further study the crosslinking mechanism that leads to the formation of a polyoxazoline network, mechanical and spectroscopic changes during the curing process have been investigated.

Whether a successful crosslinking reaction has taken place according to the mechanism shown in Fig. 2, is determined using IR spectroscopy. Additionally, to prove successful crosslinking, storage and loss modulus for uncatalyzed as well as catalyzed samples and temperature-dependent oscillating rheological measurement are discussed, too.

Upon curing of adduct 2 at temperatures higher than $160^{\circ} \mathrm{C}$ and via acid catalysis, the formation of a hard coating is observed.
IR spectra (Figs. 3, 4, and 5) are baseline corrected and normalized on the $\mathrm{C}-\mathrm{N}$-stretch signal of the isocyanurate at $765 \mathrm{~cm}^{-1}$ as this signal does not change during the network formation. ${ }^{10}$

Successful cationic polymerization has taken place as can be detected from the increase of the $\mathrm{N}-\mathrm{H}$ signal at $3330 \mathrm{~cm}^{-1}$ caused by the new amide group with a N$\mathrm{H}$-group, which is formed during the ring opening process (compare Fig. 2). During the polymerization of 2, it can be assumed that many short-chain polymer chains are formed due to the steric hindrance during the polymerization. These have an $\mathrm{NH}$ bond at the start and end of the chain, which can be detected by means of IR. 
In the spectrum of $\mathbf{2}$, the amide I vibration of the urethane/isocyanurate group can be detected at $1712 \mathrm{~cm}^{-1}$ and $1680 \mathrm{~cm}^{-1}$ with the corresponding amide II or $\mathrm{N}-\mathrm{H}-$ signal at $1531 \mathrm{~cm}^{-1}$ caused by the $\mathrm{N}-\mathrm{H}$ group of the urethane groups (Fig. 4). An amide II signal is visible, if at least one proton is bounded at the nitrogen of the amide group, therefore this signal proves the formation or existence of an amide group with an $\mathrm{N}-\mathrm{H}$-group. ${ }^{10}$

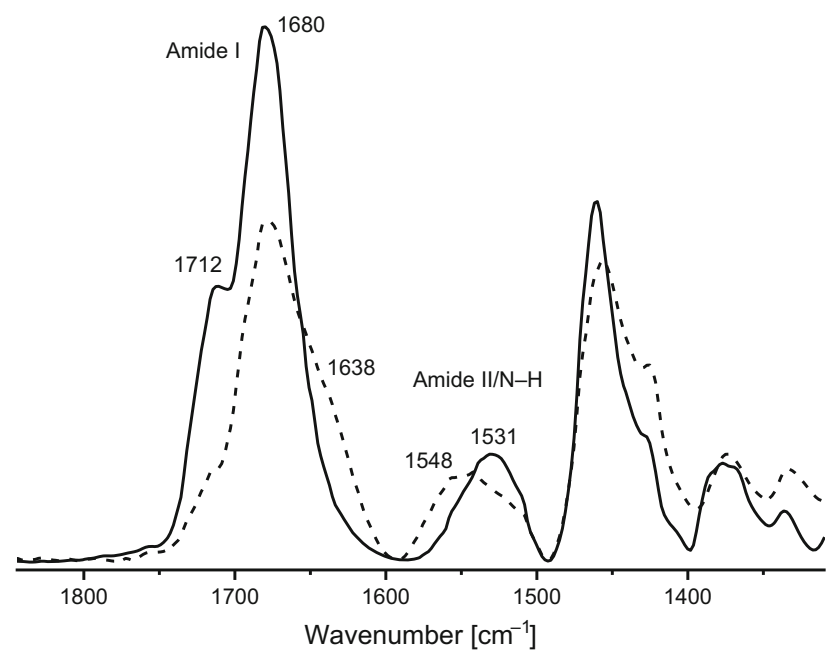

Fig. 4: Enlargement of Fig. 3 from 1300 to $1800 \mathrm{~cm}^{-1}$
In the spectrum of $\mathbf{3}$, a new amide I signal is visible with the shoulder visible in Fig. 4 at $1638 \mathrm{~cm}^{-1}$, which proves the formation of N,N-di-substituted amides. ${ }^{10}$

The amide II or N-H vibrations are shifted to 1548 $\mathrm{cm}^{-1}$ (Fig. 4) as the formation of new amide groups lead to an increasing number of $\mathrm{N}-\mathrm{H}$ groups in the network, which further proves the mechanism of the crosslinking reaction according to Fig. 2.

Finally, the ether group in the oxazoline ring disappears upon crosslinking. In Fig. 5 the reduced signal in the cured sample at $1038 \mathrm{~cm}^{-1}$ for the $=\mathrm{C}-\mathrm{O}-$ $\mathrm{C}$ group is illustrated.

With that, the cationic polymerization of oxazoline moieties and crosslinking of $\mathbf{2}$ can be verified according to the mechanism of Fig. 2.

To further prove whether chemical crosslinking of 2 takes place upon curing rather than physical drying of the prepared films at elevated temperatures, sol-gel analysis has been carried out.

After curing of 2 in the presence of $\mathrm{SnCl}_{4}$ as a catalyst at $190^{\circ} \mathrm{C}$ for $30 \mathrm{~min}$, extraction of the resulting polymeric network 3 with MEK in a Soxhlet extractor is performed. A remaining gel fraction of $98.1 \pm 0.3 \%$ is obtained for the $\mathrm{SnCl}_{4}$-catalyzed sample. In comparison, extraction of uncured polyisocyanate-oxazoline adduct $\mathbf{2}$ with MEK resulted in a non-measurable gel part. With this, sol-gel analysis supports the previous conclusion that a crosslinked polymer network is formed upon curing of $\mathbf{2}$ in the presence of an acidic catalyst.

The crosslinking ability of $\mathbf{2}$ in the presence of catalysts is further studied using rheological experiments to determine the modulus of the polymeric network. These oscillating experiments have to be

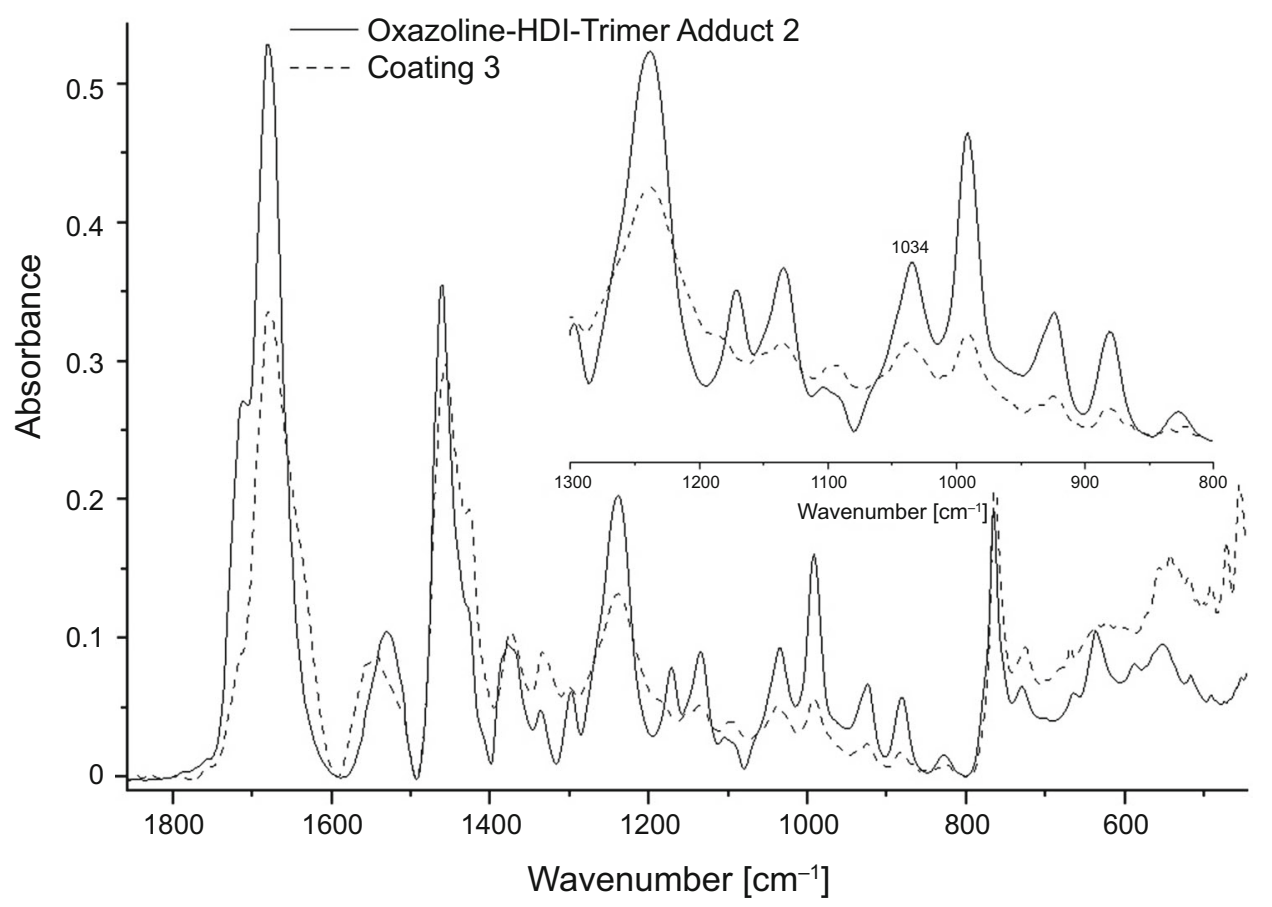

Fig. 5: Finger print range of Fig. 3 


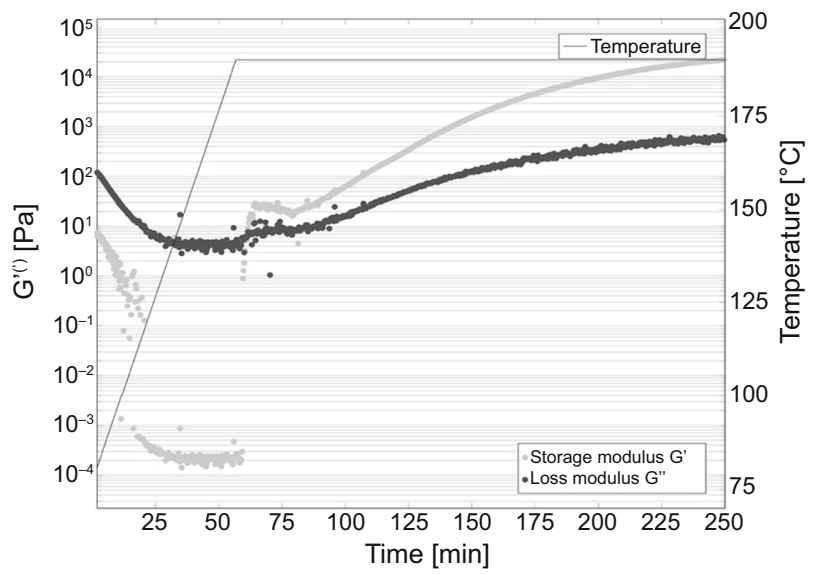

Fig. 6: DMTA (amplitude $0.1 \%$, frequency $10 \mathrm{rad} / \mathrm{s}$, temperature ramp: $2^{\circ} \mathrm{C} / \mathrm{min}$ to $190^{\circ} \mathrm{C}$ ) experiment with 2 dried over night with $0.5 \% \mathrm{SnCl}_{4}$ as catalyst

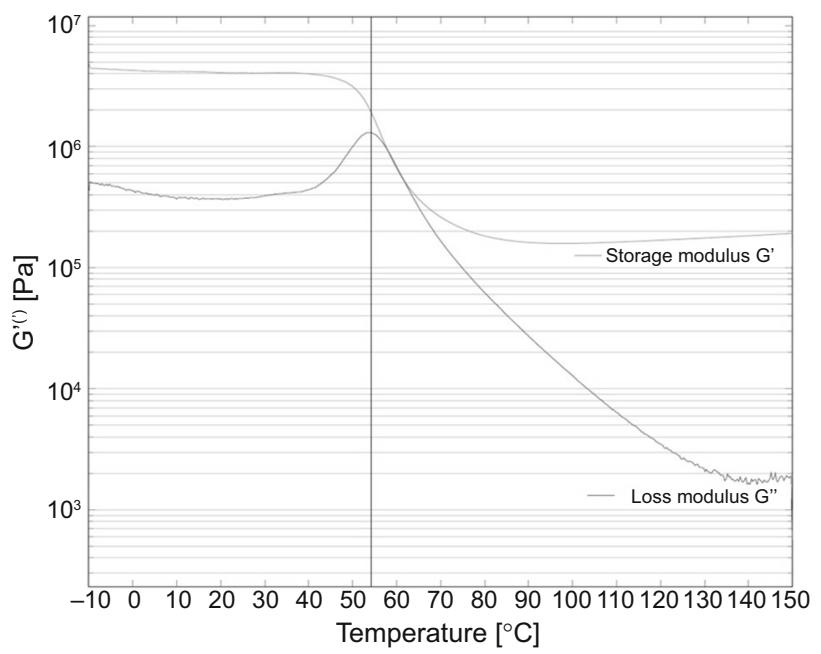

Fig. 7: Oscillation measurement (amplitude $0.1 \%$, frequency $10 \mathrm{rad} / \mathrm{s}$, temperature ramp: $2^{\circ} \mathrm{C} / \mathrm{min}$ ) after the experiment of Fig. 6 with 3 with $\mathrm{SnCl}_{4}$ as catalyst

performed in the linear viscoelastic range (LVE). ${ }^{14}$ With 2 before and after curing, it is the case with an amplitude of $\omega=10 \mathrm{rad} / \mathrm{s}$ and a frequency of $\gamma=0.001-10 \%$ and therefore all DMTA measurements have been performed with these parameters.

Upon curing, the gel-point, i.e. $G^{\prime}=G^{\prime \prime}$, of $\mathbf{2}$ is achieved immediately after heating the acid catalyzed sample to $190^{\circ} \mathrm{C}$ (Fig. 6). The network formation is visible by an increase of the storage modulus. The formed network shows a glass transition temperature of $T_{\mathrm{g}}=55^{\circ} \mathrm{C}$ (Fig. 7). The $T_{\mathrm{g}}$ is obtained in a temperature dependent measurement of $G^{\prime \prime}$ at the maximum of the curve in the second heating run. ${ }^{14}$

The $T_{\mathrm{g}}$ of physical dried acrylate coatings are in the range of $32-48^{\circ} \mathrm{C}$, whereas with the same resins cured with crosslinking agents, the resulting coatings show $T_{\mathrm{g}}$ in the range of $61-72^{\circ} \mathrm{C} .{ }^{15}$ Another example is UV

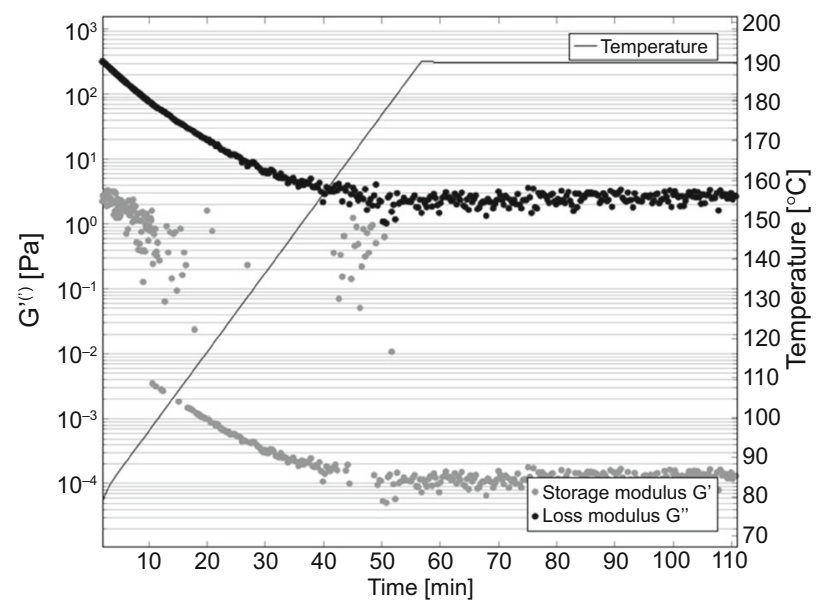

Fig. 8: Oscillation measurement (amplitude $0.1 \%$, frequency $10 \mathrm{rad} / \mathrm{s}$, temperature ramp: $2^{\circ} \mathrm{C} / \mathrm{min}$ to $190^{\circ} \mathrm{C}$ ) with compound 3 dried over night without added catalyst

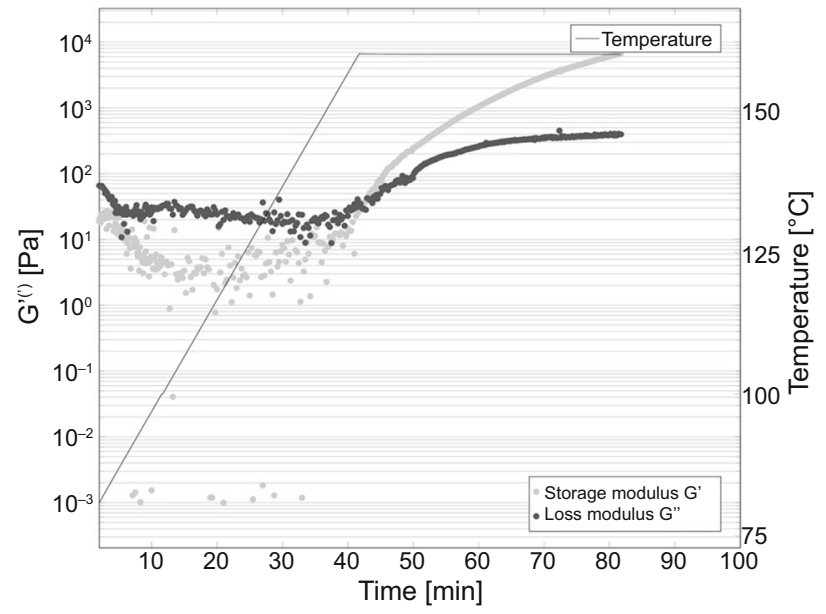

Fig. 9: DMTA (amplitude $0.1 \%$, frequency $10 \mathrm{rad} / \mathrm{s}$, temperature ramp: $2^{\circ} \mathrm{C} / \mathrm{min}$ to $160^{\circ} \mathrm{C}$ ) experiment with compound 3 dried over night with $0.5 \% \mathrm{SnCl}_{4}$ as catalyst

cured coatings. ${ }^{16}$ Resins with a low amount of double bonds show $T_{\mathrm{g}}$ values in the range of $37-43^{\circ} \mathrm{C}$ and with a high amount of double bonds, the $T_{\mathrm{g}}$ increases to values between 53 and $78^{\circ} \mathrm{C}$ depending on the amount of double bonds. As a last example, HDI-Trimer formed a network with a branched polyester with a $T_{\mathrm{g}}$ of $54^{\circ} \mathrm{C}$. $^{17}$ Therefore, the new polyurethane-polyamine/amide network is in the standard range of the glass transition temperature of crosslinked coatings with a $T_{\mathrm{g}}$ of $55^{\circ} \mathrm{C}$.

With unsuccessful crosslinking of $\mathbf{2}$ taking place in the absence of catalysts visible by a missing gel-point and no increase in the storage modulus in Fig. 8, it is of interest to study the effect of catalysts on the crosslinking behavior and the curing temperature.

Therefore, different common catalysts for cationic polymerization have been screened to catalyze the selfpolymerization as shown in Table 1, starting from $\mathrm{SnCl}_{4}$ 
to methyl tosylate. Oscillation measurements by rheometer provide values for loss and storage modulus, while baking at $160^{\circ} \mathrm{C}$ or $190^{\circ} \mathrm{C}$ to check whether crosslinking has been successful using the respective catalyst. An increase in the values for storage and loss modulus during the temperature-dependent oscillating rheological measurements would lead to the conclusion that crosslinking took place. Using $\mathrm{SnCl}_{4}$, the gel-point is achieved as soon as the samples are heated up to $160^{\circ} \mathrm{C}$ (Fig. 9).

However, using alternative catalysts, such as citric acid or methyl tosylate, network formation cannot be observed independent of the curing temperature (see supplementary material, Figs. S6-10). Network formation is possible with acetic acid at $190^{\circ} \mathrm{C}$ and with cadmium acetate at $190^{\circ} \mathrm{C}$, too. With that, a significant reduction of the curing temperature can only be achieved by addition of $\mathrm{SnCl}_{4}$.

Finding an alternative catalyst for successful reduction of the curing temperature without the need for tin compounds is a favorable goal.

Essential for the evaluation of new crosslinking reactions are the resulting properties of the final coating surface. With the focus of the crosslinking reaction, the impact test and pendulum damping have been performed to characterize the polymer network. Furthermore, the adhesion on steel has been tested, too.

Table 2 summarizes the properties of the cured coatings in dependence of different catalysts. As shown before, network formation is not possible without the addition of catalysts.

Using acidic catalysts for polymerization, such as $\mathrm{SnCl}_{4}$, high pendulum hardness values are achieved. Results of the impact test show that flexible coatings can be achieved at $190^{\circ} \mathrm{C}$, too. A physical dried compound/polymer should be brittle, but a polymer network could be hard and flexible, therefore, the impact test gives additional information to the polymer network. Crystallinity of partly not crosslinked polymers could be a reason for the low flexibility of the coating, too. Here, the impact test shows hard and flexible coatings at $190^{\circ} \mathrm{C}$ curing temperatures. In comparison to the above mentioned NIPU coatings, very hard and flexible coatings are available with polyoxazolines.

All cured coatings show an excellent adhesion with a $\mathrm{GT}=0$ on steel according to DIN EN ISO 2409. The gloss of all coatings is visually evaluated high and more or less independent of the catalyst or curing temperature.

Finally, for a first look, the resulting coatings properties are promising using oxazoline containing resins for coating application.

\section{Conclusions}

Based on commercially available raw materials, a novel oxazoline containing resin has been synthesized to form a polyisocyanate-oxazoline adduct $\mathbf{2}$, which is able to undergo self-crosslinking to a polyamide/ polyamine/polyurethane network $\mathbf{3}$.

Upon curing at elevated temperatures, polyurethane-polyamine/polyamide networks form via ringopening polymerization leading to a hard but flexible coating with good adhesion to steel and high gloss.

Acknowledgements The work was funded by the Federal Ministry of Education and Research (BMBF) and Covestro Deutschland AG through the FHProfUnt project ChemZymeCoat (FKZ 13FH 125PX6).

Funding Open Access funding enabled and organized by Projekt DEAL.

Open Access This article is licensed under a Creative Commons Attribution 4.0 International License, which permits use, sharing, adaptation, distribution and reproduction in any medium or format, as long as you give appropriate credit to the original author(s) and the source, provide a link to the Creative Commons licence, and indicate if changes were made. The images or other third party material in this article are included in the article's Creative Commons licence, unless indicated otherwise in a credit line to the material. If material is not included in the article's Creative Commons licence and your intended use is not permitted by statutory regulation or exceeds the permitted use, you will need to obtain permission directly from the copyright holder. To view a copy of this licence, visit http://creativecommons.org/licenses/b $\mathrm{y} / 4.0 /$.

Data availability The raw data required to reproduce these findings cannot be shared at this time as the data also forms part of an ongoing study.

\section{References}

1. Mischke, P, Film Formation, Vincentz Network, Hanover (2010)

2. Guan, J, Song, Y, Lin, Y, Yin, X, Zuo, M, Zhao, Y, et al. "Progress in Study of Non-Isocyanate Polyurethane." Ind. Eng. Chem. Res., 50 (11) 6517-6527 (2011). https://doi.org/10. 1021/ie101995j

3. Wunschik, DS, Ingenbosch, KN, Zähres, M, Horst, J, Mayer, C, Jäger, M, Strehmel, V, Dornbusch, M, Hoffmann-Jacobsen, K, "Biocatalytic and Solvent-free Synthesis of a Biobased Biscyclocarbonate." Green Chem., 20 4738-4745 (2018)

4. Wunschik, D, Hoffmann-Jacobsen, K, Dornbusch, M, "Lipase Catalyzed Modification of Functionalized Polymers.' Prog. Org. Coat., 20 (5) 9358-9379 (2019)

5. Kobayashi, S, Uyama, H, "Polymerization of Cyclic Imino Ethers: From Discovery to the Present State of the Art." $J$. Polym. Sci. Part A, 40192 (2001) 
6. Woodle, MC, Engbers, CM, Zalipsky, S, "New Amphipatic Polymer-Lipid Conjugates Forming Long-Circulating Reticuloendothelial System-Evading Liposomes." Bioconjugate Chem., 5493 (1994)

7. Zalipsky, S, Hansen, CB, Oaks, JM, Allen, TM, "Evaluation of Blood Clearance Rates and Biodistribution of Poly(2oxazoline)-grafted Liposomes." J. Pharm. Sci., 85 133-137 (1996)

8. Guerrero-Sanchez, C, Hoogenboom, R, Schubert, US, "Fast and "Green" Living Cationic Ring Opening Polymerization of 2-Ethyl-2-oxazoline in Ionic Liquids Under Microwave Irradiation." Chem. Commun., 363797 (2006)

9. Xavier, RJ, Prabaharan, A, "Vibrational Spectroscopic Investigations of 4,4-Dimethyl-2-oxazoline: A Density Functional Theory Approach." Spectrochim. Acta Part A Mol. Biomol. Spectrosc., 136 1530-1542 (2015)

10. Hesse, M, Meier, H, Zeeh, B, Spektroskopische Methoden in der organischen Chemie, Thieme, 8th edn. Georg Thieme Verlag, Stuttgart, New York (2011)

11. Ming, W, Tian, M, van de Grampel, RD, Melis, F, Jia, X, Loos, J, van der Linde, R, "Low Surface Energy Polymeric Films from Solventless Liquid Oligoesters and Partially Fluorinated Isocyanates." Macromolecules, 35 6920-6929 (2002)

12. Defeyt, C, Langenbacher, J, Rivenc, R, "Polyurethane Coatings Used in Twentieth Century Outdoor Painted
Sculptures. Part I: Comparative Study of Various Systems by Means of ATR-FTIR Spectroscopy." Herit. Sci., 511 (2017)

13. Aoi, K, Okada M, "Polymerization of Oxazolines." Prog. Polym. Sci., 21 (1) 151-208 (1996). https://doi.org/10.1016/ 0079-6700(95)00020-8

14. Mezger, TG, Angewandte Rheologie. Anton Paar GmbH, Österreich (2014)

15. Ma, X, Qiao, Z, Huang, Z, Jing, X, "The Dependence of Pendulum Hardness on the Thickness of Acrylic Coating." $J$. Coat. Technol. Res., 10 (3) 433-439 (2013)

16. Paquet, C, Schmitt, T, Klemberg-Sapieha, JE, Morin, J-F, Landry, V, "Self-Healing UV Curable Acrylate Coatings for Wood Finishing System, Part 1: Impact of the Formulation on Self-Healing Efficiency." Coatings, 10770 (2020). http s://doi.org/10.3390/coatings10080770

17. Matner, M, Casselmann, H, Zhuang, W, Achten, D, Ehlers, M, "Transparent Polyurethanes with High Glass Transition Temperature Tg." US020150246998A1

Publisher's Note Springer Nature remains neutral with regard to jurisdictional claims in published maps and institutional affiliations. 